\title{
Hidden Power of Yoga in COVID19: A cross sectional study
}

\author{
Research Article
}

\section{Vijay Mohan Soni', Shiv Singh², Neha Munjal ${ }^{3 *}$}

\section{Medical Officer, Uni-Hospital, Lovely Faculty of Applied Medical Sciences (LFAMS),}

Lovely Professional University, G. T. Rd, Phagwara, Punjab, India.

2. Assistant Librarian, Department of Library, Bennett University (Times of India Group), Greater Noida, Uttar Pradesh, India.

3. Assistant Professor, Department of Physics, School of Chemical Engineering and Physical Sciences, Lovely Professional University, G. T. Rd, Phagwara, Punjab, India.

\begin{abstract}
The world is under the various psychological diseases because of the ongoing COVID-19 pandemic. The whole world is suffering from stress and anxiety as the future is unprecedented. In this tough time, people are trying to adopt various activities to keep themselves free from stress and to enhance the immunity levels. For this they are valuing the traditional practices of our Indian heritages such Ayurveda and Yoga. Therefore, to know the perception of common population of Greater Faridabad, Haryana towards the Yogic practices, this study has been conducted during this pandemic in which total 395 participants of both genders took part. The evidence indicated that younger people have more belief and interest in Yogic Practices than elderly people. The result has a significant difference at 0.05 level of confidence. Furthermore, the hypothesis has been accepted that Yoga has a potential to manage the health and immunity.
\end{abstract}

Key Words: COVID-19, Immunity, Stress, Yoga, Pandemic, Faridabad.

\section{Introduction}

In this pandemic everyone is facing the lot of stress, pressure, tension, physical pressure as well as mental fatigue etc. because of sudden new normal. Every individual has a different capacity of coping with stress. To some extent stress is good, but the constant stress can lead to the weaker immune system and more susceptible to infections as during stressful conditions, the ability of immune system to repel the antigens is reduced. The stress hormone corticosteroid can suppress the effectiveness of the immune system (e.g. lowers the number of lymphocytes).

Yoga is welcomed by the world over for its health promoting and wellness creating aspects. Yoga helps to provide the holistic framework for the health of individuals by interconnecting the mind, body and creating the balance. Several yogic techniques are there for enhancing the will power and mastering the mind for keeping immune system strong, such as asana, pranayama, meditation and detoxification through kriyas. In addition to this Pratipaksha Bhavana (contrary attitude) is recommended in the yoga literature.

\section{* Corresponding Author:}

\section{Neha Munjal}

Assistant Professor, Department of Physics, School of Chemical Engineering and Physical Sciences,

Lovely Professional University,

Punjab, India.

Email Id: neha.18869@1pu.co.in
The yogic techniques help the mind to replace the negative thoughts with positive thoughts (prashamana). All Yogic practices includes deep relaxation, which helps to release all tensions and boosts immune system.

Henceforth, Yoga for stress reduction and immune modulation is the best alternative in this pandemic for the whole world. It should be practiced daily for healthy living instead of only on the international yoga day.

\section{Methodology}

In order to analyze the beliefs on the Yoga system the present study have been conducted by designing unidirectional (Positive) questionnaire having dichotomous questions. The team of 5 yoga experts was created and they went to 5 different zones of Greater Faridabad, Haryana. The sample selection criteria included the interview and observation method and the sample chosen included the people with stress related to job, pandemic, family or any other factor. The methodology which has been used to conduct is "Single-blind randomized controlled Research Trial". A total of 450 questionnaires were distributed (1 1 st October 2020-15th October 2020), out of which 395 filled positive responses were received. The age of the participants ranged from 30 to 60 years including males and females. The participants were divided into four categories for analyzing the data:

1.Males having age from $30-45$ years (108)

2.Females having age from $30-45$ years (78)

3.Males having age from 46-60 years $(122)$

4.Females having age from $46-60$ years (87) 
These participants were requested to do Yoga for one month (1st Nov 2020 to 30th Nov 2020), the various list of yoga module, which was followed is mentioned in Table 1

Looking to the COVID pandemic, the sessions were conducted in the various groups at different yoga centers/gym. The overall attendance of the participants was $94.12 \%$ which is on higher side and it reflects the positive attitude towards the yoga practices.

\section{Table 1: Yogic techniques}

Recitation of Aum

2 Yogic Shatkarma [Kapalbhathi (Shinning of $10 \mathrm{~min}$

forehead), Nauli (Abdominal Massage)]

Joint loosening practices (warming up $10 \mathrm{~min}$

exercises)

Selected Asana (2 standing pose, 2 sitting pose $15 \mathrm{~min}$

and 2 balancing pose)

Yogic pranayama

Meditation

$10 \mathrm{~min}$

$5 \mathrm{~min}$

Yoga Nidra/ Shavasana

\section{Data Interpretation}

This study showed significant attendance at $95 \%$ level of confidence, which reflects that the people, residing in Greater Faridabad (Haryana) have a positive and favourable attitude towards Yoga after a 60 minute session (Table 1). The various sessions were conducted daily early in the morning from 5:30 to 8:30 A.M. in a small group by maintaining the protocols of COVID19.

The older generation of the age group $46-60$ had much favourable mindsets towards Yoga. Among them Males were more sincere as compared to the females. The statistical calculation showed that there is significant difference between the attitude towards Yogic practices (Table2) in context to age groups as well as gender. The overall attitude of all the respondents was on the positive side, but the Males in the age category of $46-60$ years have the most favourable attitude and the belief towards the Yoga, this is clearly reflected by their attendance also.

Table2-Attendance of participants in Yoga sessions

One-Sample Statistics

Attendance Male (Age 30-45)

Attendance Female (Age 30-45)

Attendance Male (Age 46-60)

Attendance Female (Age 46-60)

$\mathbf{N}$
108
78
122
87

Mean
27.963
27.5385
29.0574
28.0345

Std. Deviation

2.7545
1.6956
0.806
1.4899

Test; Test Value $=27$

\begin{tabular}{|c|c|}
\hline $\mathbf{t}$ & $\mathbf{d}$ \\
\hline 3.6326 & 107 \\
\hline 2.8047 & 77 \\
\hline 28.1836 & 121 \\
\hline 6.4772 & 86 \\
\hline
\end{tabular}

Std. Error Mean

0.2651

0.1920

0.0730

0.1597

\begin{tabular}{|c|c|}
\hline df & Critical Value \\
\hline 107 & -1.6592 \\
\hline 77 & -1.6649 \\
\hline 121 & -1.6575 \\
\hline 86 & -1.6628 \\
\hline
\end{tabular}

Attendance Male (Age 30-45)

Attendance Female (Age 30-45)

Attendance Male (Age 46-60)

Attendance Female (Age 46-60)
One-Sample Test

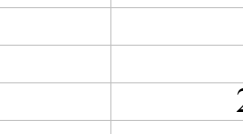

\section{Table2-Attitude of participants towards Yoga practices} One-Sample Statistics

\begin{tabular}{|c|c|c|c|c|}
\hline & $\mathbf{N}$ & Mean & Std. Deviation & Std. Error Mean \\
\hline Attitude of Male (Age 30-45) & 108 & 8.5741 & 1.1291 & 0.1086 \\
\hline Attitude of Female (Age 30-45) & 78 & 8.1282 & 1.3129 & 0.1486 \\
\hline Attitude of Male (Age 46-60) & 122 & 8.9098 & 0.8332 & 0.0754 \\
\hline Attitude of Female (Age 46-60) & 87 & 9.5287 & 0.5021 & 0.0538 \\
\hline \multicolumn{5}{|c|}{ One-Sample Test; Test Value $=8$} \\
\hline & & $\mathrm{T}$ & df & Critical value \\
\hline Attitude of Male (Age 30-45) & & 5.2864 & 107 & -1.6592 \\
\hline Attitude of Female (Age 30-45) & & 0.8627 & 77 & -1.6649 \\
\hline Attitude of Male (Age 46-60) & & 12.0663 & 121 & -1.6575 \\
\hline Attitude of Female (Age 46-60) & & 28.4145 & 86 & -1.6628 \\
\hline
\end{tabular}

One-Sample Test; Test Value $=8$

Table 3: Attitude of two age Groups (ANOVA)

\begin{tabular}{|l|c|c|c|c|c|c|}
\hline Source of Variation & SS & Df & MS & F & P-value & F crit \\
\hline Between Groups & 59.93221 & 1 & 59.93221 & 58.40625 & $1.65 \mathrm{E}-13$ & 3.865229 \\
\hline Within Groups & 403.2678 & 393 & 1.026127 & & \\
\hline Total & 463.2 & 394 & & & \\
\hline
\end{tabular}

The one way ANOVA is used to compare the attitudes of the two different set of age groups under consideration. In this comparative chart of attitude of different age group reflected that there is significant difference between the attitudes among the age group. The older people (Age 46-60) have the positive attitude and are more sincere towards the yoga session. There is the strong correlation between the attendance and the attitude towards Yoga Session. Perhaps both the groups took part and get benefited with overall health (physical and mental both). The result has a significant difference at 0.05 level of confidence. Thus, the hypothesis is accepted that Yoga has a potential to defence the overall management of health and immunity in adults and elderly people. 
Henceforth, the survey and analysis indicated that there is the inclination towards the traditional system of Yoga and public feels its important techniques to relive the stress and is much needed for the healthy living. Most of the people of Greater Faridabad (about $42 \%$ ) who practice Yoga have an interest to keep fit only through Yoga and about $27 \%$ of people do yogic practices to cure certain chronic diseases. It is important to mention that $75 \%$ of the people started the Yoga in the Pandemic to alleviate natural immunity. The respondents shared their experience after the Yogic session that they are feeling wellness both physically and mentally. $10 \%$ of respondents also shared that they are feeling therapeutic value on digestive system, circulatory system, nervous system, and metabolism. 2 percent of them felt that their Cardio-vascular system has improved.

\section{Conclusion}

Thus, we can conclude that both the groups have almost positive mindset and enthusiasm towards the practice of Yoga as well as the belief on the traditional Yoga System during the COVID-19 pandemic. Henceforth, Yogic practices helps to establish balance systematically and scientifically, It is suggested that every individual should follow the eight steps of Ashtanga Yoga i.e., Yama, Niyama, Asana, Pranayama, Pratyahara, Dharna, Dhyana and Samadhi. Further, the Yogic concentration helps to increase the meditative capacity, which kills Ruj (pain), Klesha or sorrows, Icha (desires). Henceforth, Yogic techniques are ideal for the preventive, promotive, curative and the rehabilitative aspects of health.

\section{Acknowledgement}

Authors acknowledge the immense help received from the scholars whose articles are cited and included in references of this manuscript. The authors are also grateful to authors / editors / publishers of all those articles, journals, and books from where the literature for this article has been reviewed and discussed. The entire project was self-financed to evaluate the attitude of the Indian population towards Yogic Practices during this global Pandemic of COVID-19. We would like to thank all the participants and the team who gave us support to evaluate the entire study.

\section{Conflict of Interest} NIL

\section{Authors Contribution Statement}

The concept and idea were of Vijay Mohan Soni. The final drafting and setting the reference was done by Shiv Singh. The design of intervention, data collection and data analysis was done by Neha Munjal.

\section{References}

1. Bera TK, Gore MM, Oak JP. Recovery from stress in two different postures and in Shavasana-A yogic relaxation posture. Indian J Physiol and Pharmacol. 1998 Oct 1;42:473-8.

2. Bhavanani AB. A Yogic approach to stress. Dhivyananda Creations, Iyyanar Nagar, Pondicherry. 2008; 29.

3. BhavananiA B. Combating Techno Stress Through Yoga, Procin National Yogaweek. 2010: 210-4.

4. Bushell W, Castle R, Williams MA, Brouwer KC, Tanzi RE, Chopra D, Mills PJ. Meditation and yoga practices as potential adjunctive treatment of SARS-CoV-2 infection and COVID-19: a brief overview of key subjects. J Altern Complement Med. 2020 Jul 1;26(7):547-56.

5. Girija PL, Sivan N. Ayurvedic treatment of COVID-19/SARS-CoV-2: A case report. J Ayurveda Integer Med. 2020 Jun 19.

6. https://patanjaliyogasutra.in/ (Accessed 02-04-2021)

7. https://www.ayush.gov.in/ (Accessed 02-04-2021)

8. https://www.who.int/emergencies/diseases/novelcoronavirus-2019 (accessed 01-04-2021)

9. Joyner MJ, Casey DP. Regulation of increased blood flow (hyperemia) to muscles during exercise: a hierarchy of competing physiological needs. Physiol rev. 2015 Apr 1: 549-601.

10. NagendraHR. Yoga for COVID-19. Int J Yoga. 2020 May;13(2):87.

11. Ransing R, da Costa MP, Adiukwu F, Grandinetti P, Teixeira AL, Kilic O, Soler-Vidal J, Ramalho R. Yoga for COVID-19 and natural disaster related mental health issues: challenges and perspectives. Asian J Psychiatr. 2020 Oct 1.

12. SinhaP, Yogic cure for common diseases, Orient paper books,New Delhi, 1994.

13. Tillu G, Chaturvedi S, Chopra A, Patwardhan B. Public health approach of Ayurveda and yoga for COVID-19 prophylaxis. J Alter Complement Med. 2020 May 1;26(5):360-4.

14. Verma S \& Kumar K. Evidence-based comparative study of group and individual consciousnes son life satisfaction among adults, YogaMimansa, 2020:52(1)34-7.

15. Verma S, Kumar K, Meena R. Evidenced Based Study On General Wellbeing Through Hath Yoga. Int J Sci Consciousness. 2017;3(4):78-83. 